\title{
Development of Spatial Ability According to Mental Rotation Test AT SKF AND YBL
}

\author{
András Zsolt Kovács ${ }^{1,2}$, László Németh ${ }^{3}$ \\ ${ }^{1}$ Institute of Architecture, Ybl Miklós Faculty of Architecture and Civil Engineering, \\ Szent István University, Budapest, Hungary \\ kovacs.andras.zsolt@ybl.szie.hu \\ ${ }^{2}$ Department of Architectural Representation, \\ Faculty of Architecture, Budapest University of Technology and Economics, Budapest, Hungary \\ kovacsazs@arch.bme.hu \\ ${ }^{3}$ Institute of Mathematics, Faculty of Forestry, University of West Hungary, Sopron, Hungary \\ lnemeth@emk.nyme.hu
}

\begin{abstract}
The Mental Rotation Test (MRT) is one of the tests to survey the spatial ability. In this article we make an attempt to measure the spatial abilities of the students of wood industrial engineering and industrial design engineering of the Simonyi Károly Faculty of Engineering, Wood Sciences and Applied Arts (SKF for short) of the University of West Hungary and compare the results with the architects students of the Ybl Miklós Faculty of Architecture and Civil Engineering of the Szent István University. The paper aims to compare the results with respect to the scores and mainly the improvement based on new examination aspects. The article concludes that the small differences in the students' developments of spatial ability in the two institutions can be caused by the difference in Descriptive Geometry courses.
\end{abstract}

Keywords: Mental Rotation Test, MRT, Descriptive Geometry education, spatial ability.

\section{INTRODUCTION}

We can agree that having a good spatial ability is one of the most important abilities of a skilled engineer. Nowadays making the most of the continuously developing computer CAD systems also requires perfect spatial abilities. Researchers have developed several tests to measure this ability, such as Mental Rotation Test (MRT) introduced by Shepard and Metzler [6] in 1971. As the ability of mental rotation is only a part of spatial ability, the MRT measures only one part of spatial ability. Researchers use some other tests too. The most often applied one is the Mental Cutting Test (MCT). A survey has proved [8] that descriptive geometry studies improve spatial ability. Other surveys pointed out that the results of men are better than the results of women considering the same tests and conditions. It was published first in [7].

A longer description of the history and methods of examining spatial ability can be found in $[1,2]$. 
In this article we show the survey of the mental rotation of spatial abilities of the students of wood industrial engineering and industrial design engineering of the Simonyi Károly Faculty of Engineering, Wood Sciences and Applied Arts (SKF for short) of the University of West Hungary in Sopron. Our survey connected to Descriptive Geometry in the academic year 2013/14 was the first test in its kind as the spatial abilities of the engineer students at SKF have not been measured before. In this article we also analyse the survey of the architect students at the Ybl Miklós Faculty of Architecture and Civil Engineering of Szent István University in Budapest in the same academic year. Now we publish the comparative survey of tests done parallel in the two universities, laying stress on the development of spatial ability, which has not been examined so carefully before. In our survey we also examine the development of spatial ability of the two genders separately. A study has been appeared on the base of the parallel surveys by MRT at the Ybl and the University of Ljubljana [1]. This survey done in the academic year 2012/13 found the similar results for both institutions, and on the base of the authors' opinions its reason was probably the same teaching material.

The students were required to write the MRT tests on the first and on the final Descriptive Geometry lessons of the semester, as it is the subject that develops most spatial ability [8]. The conditions of the survey were the same as in [1]. The MRT test had two pages with 10 items on each page. The students got 3 minutes to prepare each, and they were not allowed to turn the sheet even if they had finished the first side in less than 3 minutes. Their task was to choose the two correct alternatives from among the four possible images. If a student could find only one correct structure, he had the opportunity to mark only one. In scoring the tests we changed from the usual „Answer Key for MRT” to the system used in [1]. According to recommended scoring, two points are given if both choices of the student are correct, and one point if the student marked only one structure, but that is correct. No point is given in any other cases. The new scoring system differs from the above described one slightly and gives fairer results. The new system is:

-2 points, if both answers are correct,

$-3 / 4$ points, if one of the answers is correct, but the other one is incorrect,

$-5 / 4$ points, if there is only one answer, and that is correct,

- no points in any other cases.

\section{MRT SURVEY IN SOPRON}

The BSc students of wood industrial engineering and industrial design engineering of SKF in Sopron study Descriptive Geometry only for one semester, three lessons a week. (The short summary of the teaching material: the bases of the Monge- and axonometric projections; the description of common surfaces often used in technical drawings - pyramid, prism, cylinder, cone, sphere -, their plane sections and intersections; perspective projection.) The number of students was 57 the first time, in September 2013, and in December 2013 as well. The number of the students who took part in both tests was only 51 . Table 1 gives the mean score of the students' results. 


\begin{tabular}{|l|c|c|c|}
\hline SKF (Sopron) & September & December & Difference \\
\hline Overall (57 persons) & 21.32 & 26.37 & 5.05 \\
\hline Males (45 persons) & 22.73 & 27.8 & 5.07 \\
\hline Females (12 persons) & 16 & 21 & 5 \\
\hline
\end{tabular}

Table 1. Mean scores of MRT at SKF

We can see that in accordance with previous studies at other universities ([1], [4]), the achievement of female students is significantly poorer than male students'. Moreover, the average result of female students is worse even after studying a semester of Descriptive Geometry than their male mates' ability without studying this subject (see Table 1). Their score was even less than the average score in September. But we can also conclude that according to MRT the spatial abilities improved by almost the same amount, 5 points, in case of both male and female students during the semester.

We examine first whether the results of the MRT test follows the normal distribution. The connection of the MRT test and the normal distribution was first discussed in [1] and [3]. We arranged the students having taken part in the survey on the base of their scores into 14 classes, by 3 points. The classes are marked with their middle values, except the last class, that contains the students, who achieved 39 or 40 points. Figures 1, 2 and 3 show the histograms of our results on the base of this classification in September and December. Conspicuous, that relatively many male students achieved 19 ( \pm 1 point) in September. (The same tendency can be seen among the female students too, although it means only one person more in class 19 than in class 13.) Almost one third of the students had the same spatial ability at the beginning of their Descriptive Geometry studies. A possible explanation can be that most of the students came from technical schools for wood industry, where they had studied on the base of the same syllabus. The peak in the male's results in September seems to be balanced on the base of the second test, more students appear in the higher classes. In case of women this extreme data moves only one class upwards.

Distribution

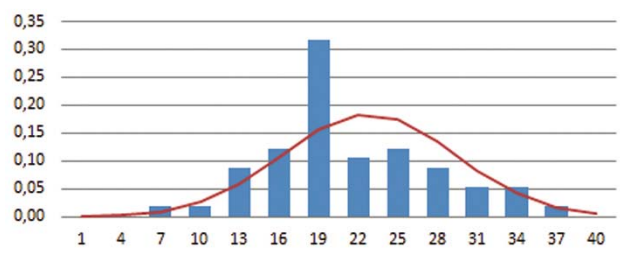

Distribution

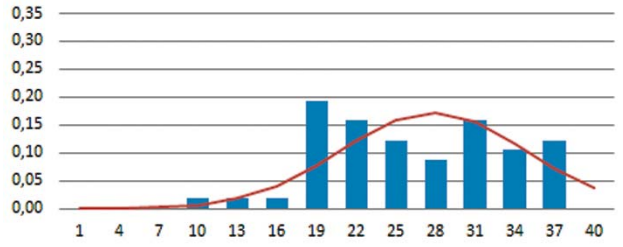

Figure 1. Distributions of the results in Sopron in September and in December

Distribution

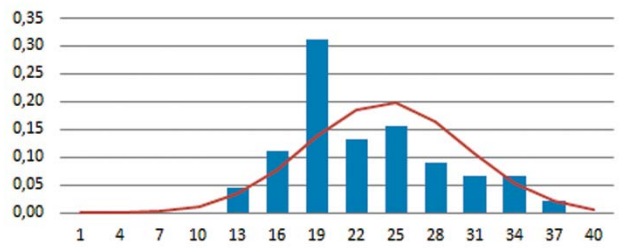

Distribution

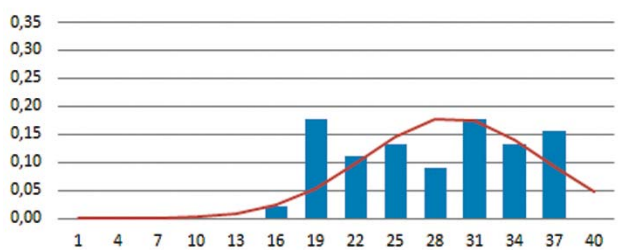

Figure 2. Distributions of the results of men in Sopron in September and in December 
Distribution

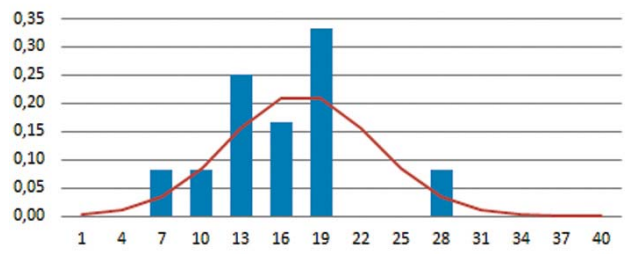

Distribution

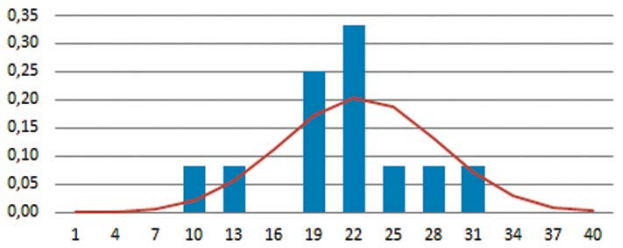

Figure 3. Distributions of the results of women in Sopron in September and in December

For examining the connection between the distributions and the normal distribution, we used the aspects described in [1]. Parameters for the most probable normal distribution are $m \approx$ sample mean and $\sigma \approx$ corrected sample standard. If $g_{i}$ denotes frequency and $b_{i}$ denotes estimated frequency of the corresponding, estimated normal distribution, then by the help of $\chi^{2}=\sum_{i=1}^{14} \frac{\left(g_{i}-b_{i}\right)^{2}}{b_{i}}$, that is a distribution $\chi^{2}$ with 11 degrees of freedom we can conclude, that all the results of overall, men and women in September can be estimated by a normal distribution at the most commonly used $95 \%$ significance level. While in December only the women's results can be estimated by the normal distribution, but at the $98 \%$ significance level both the men's and the overall's results can be. It satisfies, that the graph of the scores of male students has several peaks in December and such the graph of overall students as well. If we had used the earlier scoring system from „Answer Key for MRT”, the distributions would have been even less close to the normal distribution as it had happened in [1], when the authors had obtained better results considering the normal distribution after having introduced their new scoring system.

\section{MRT TEST AT THE YBL}

We examined in the same academic year and with the same conditions the spatial ability of the architect students at the Ybl Miklós Faculty of Architecture and Civil Engineering of Szent István University in Budapest. The tests were also written in the Descriptive Geometry classes both in September and in December. The students in Budapest study two semesters of Descriptive Geometry as a basic subject, but our examination covers only their results before and after the first semester, similarly to the students in Sopron. (The short summary of the teaching material at YBL: the bases of the Monge- and axonometric projections; sections and intersections of polyhedra; polyhedra modelling; metrical exercises; orthogonal axonometry; perspective projection; drawing of shadows.) Table 2 shows the results of their tests. There were much more students who took part in this survey in Budapest than in Sopron, but there were also several students, who could write only one of the tests. We can see from the table that the results of female students are lower than their male mates, and even their points in December cannot reach the men's results in September. 


\begin{tabular}{|l|l|c|c|}
\hline Ybl architects & \multicolumn{1}{|c|}{ September } & December & Difference \\
\hline Overall & $21.01(124$ persons $)$ & $24.05(66$ persons $)$ & 3.04 \\
\hline Males & $23.02(62$ persons $)$ & $27.08(26$ persons $)$ & 4.06 \\
\hline Females & $19(62$ persons $)$ & $22.08(40$ persons $)$ & 3.08 \\
\hline
\end{tabular}

Table 2. Mean scores of the MRT test at Ybl

Examining the distribution of the architect students, we can find that there were no extreme datas in the sample. An interesting point is that in December there were no male students in class 25 , which was almost the average class, and similarly, there were no female students in the 31 points class. We can also see that all the MRT results can be estimated by a normal distribution at the $95 \%$ significance level. (The new scoring system [1] gives better result than the previous one.) Except from the results of women in September these figures are higher than the figures showing the results of the students in Sopron. The distribution graphs spread more. There were students at $\mathrm{Ybl}$ who achieved very bad points and others who achieved very good points, while the test results of the students at SKF differed less from the average point. There were no students with extremely bad or good spatial abilities in Sopron. More students with good spatial abilities started their Descriptive Geometry studies at Ybl, than at SKF. (Comparing the results to the results in previous years [1], the mean score of students in Sopron in September was the lowest ever. We cannot compare our results with other previous results because of our new evaluation system.) The reason of it can be that there are several students among the architect students who had been studied Descriptive Geometry before.

Distribution

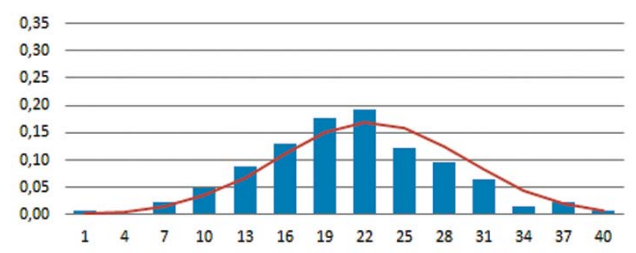

Distribution

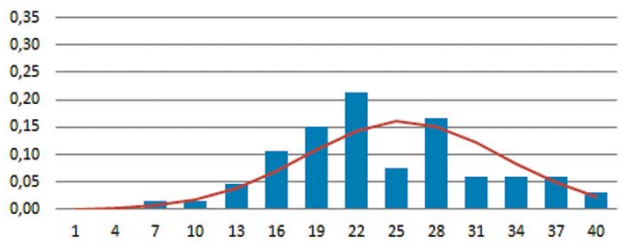

Figure 4. Distributions of the results in Budapest in September and in December

Distribution

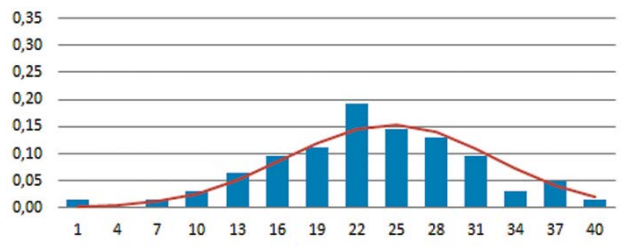

Distribution

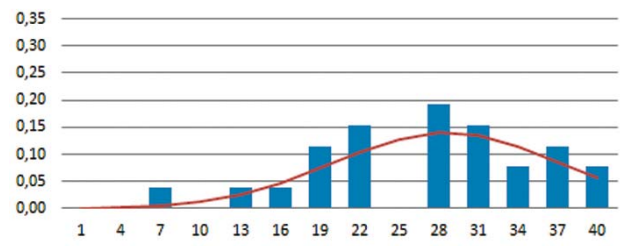

Figure 5. Distributions of the results of men in Budapest in September and in December 


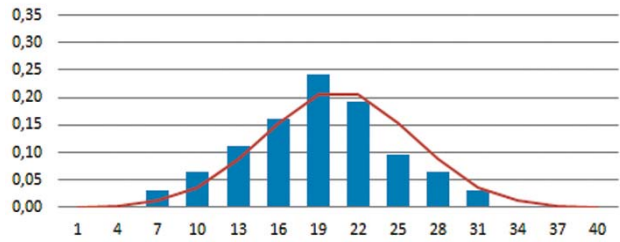

Distribution

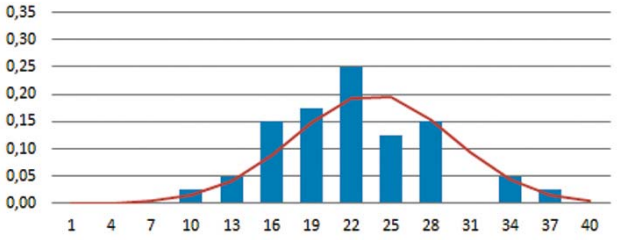

Figure 6. Distributions of the results of women in Budapest in September and in December

\section{EXAMINATION OF DEVELOPMENT OF SPATIAL ABILITIES, COMPARISON.}

In this chapter we take into consideration only those students who took part in both tests. There were 66 such students in Budapest and 51 in Sopron. We examine the development of students during their first semester study and compare it considering the two majors. We suppose that after a semester study of Descriptive Geometry the spatial abilities of the students have improved, and not decreased in any way. Despite our hypothesis there were some students who achieved much less points in December than in September. We think they did not take the second test seriously, their results are unreal. We eliminate those students from the further survey whose results became much worse, 4 or more points less, than first. Thus we examine 64 students from Budapest and 51 from Sopron.

In measuring the development we use the same aspects as in [3], we take into consideration that development from a higher opening point is more difficult than from a lower one. The same number of extra points worth more in the development from a relatively higher opening score (around the maximum). A so called level of saturation was introduced in [3] by the authors for measuring the improvement. If $h$ is the change in the number of received points in the test and $m$ is the number of points still achievable, then $a=(h / m)^{2}$ denotes the level of saturation.

We classified the students into three different categories on the base of the difference in their results in September and December: improve, stay and worsen. Those persons whose results changed only with not more than $1 \%$ considering the level of saturation belong to the group stay.
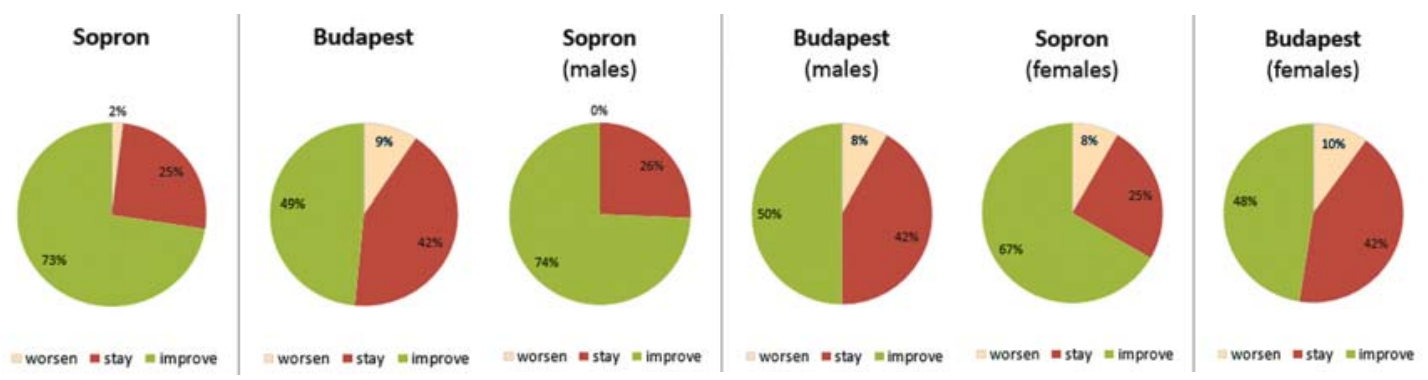

Figure 7. Development: overall, males, females 
Test result has improved in case of a considerable number of students during the semester (see Figure 7). The ratio of these students is much higher, $73 \%$ in Sopron, than in Budapest, where this figure is $49 \%$. (Without the $1 \%$ threshold value of saturation these figures would be even bigger, $82 \%$ and $66 \%$.). In accordance with our hypothesis the number of students at SKF who achieved worse scores is negligible, only $2 \%$. Actually it means one female student. While the range of students at Ybl was higher, 9\% (6 persons), 4 of them were females. If we take into consideration the diagrams for males and females only, we can find that the number of improvers was less than average in case of female students. The difference of percentages is bigger in Sopron, but because of the relatively small number of students, the $8 \%$ who worsened, means only 1 person. We will accept it as similarity too.

We can conclude that the proportion of improvers was similar in both institutions comparing the different genders in the same university. But the proportion of improvers overall was much higher in Sopron than in Budapest. The difference can be caused by the difference in teaching material and teaching period. As there is only one semester for teaching the basics of Descriptive Geometry at SKF in contrast with the two semesters at Ybl, students are taught there in small groups, by means of several easier practical problems, with less theoretical part of Descriptive Geometry. On the contrary, students in Budapest study the subject thoroughly, more detailed with more theoretical knowledge. It is important for the thorough acquisition of Descriptive Geometry, but it may develop spatial ability a bit slower. Moreover, at SKF the students have sketching in three lessons a week as a subject, it can possibly improve the spatial ability too. We also have to mention that at YBL in the second semester of 2012/13 the average result rose over 30 points and $80 \%$ of the students improved their scores, their spatial abilities and there was only one student who worsened at all (see Table 5).

According to their scores in September we formulated four further classes. Namely: poor, under average, above average and good. It is not an easy task to say who has good spatial ability. Where should we draw the limit and consider the worse test results bad? We did not give absolute categories beforehand. We decided to choose the limits of the categories on the base of the students' results. The average score and \pm the standard deviation gave the limits of the categories. The mean score of all the students of both universities in September was 21.1, and the standard deviation 6.8 , so the limits of the classes are $0-14,15-21,22-28,29-40$, respectively. We counted how many students belong to the different classes at the two faculties according to improve, stay and worsen categories, and the results can be found in Table 3 and 4. The figures give the number of students belonging to each class.

\begin{tabular}{|c|c|c|c|c|c|r|}
\hline SKF & poor & under average & above average & good & sum & \\
\hline worsen & 1 & 0 & 0 & 0 & 1 & $1.96 \%$ \\
\hline stay & 0 & 7 & 4 & 2 & 13 & $25.49 \%$ \\
\hline improve & 6 & 15 & 11 & 5 & 37 & $72.55 \%$ \\
\hline sum & 7 & 22 & 15 & 7 & 51 & $100 \%$ \\
\hline & $13.73 \%$ & $43.14 \%$ & $29.41 \%$ & $13.73 \%$ & $100 \%$ & \\
\hline
\end{tabular}

Table 3. MRT results at SKF 


\begin{tabular}{|c|c|c|c|c|c|r|}
\hline Ybl & poor & under average & above average & good & sum & \\
\hline worsen & 1 & 4 & 1 & 0 & 6 & $9.38 \%$ \\
\hline stay & 3 & 11 & 10 & 3 & 27 & $42.19 \%$ \\
\hline improve & 4 & 13 & 9 & 5 & 31 & $48.43 \%$ \\
\hline sum & 8 & 28 & 20 & 8 & 64 & $100 \%$ \\
\hline & $12.50 \%$ & $43.75 \%$ & $31.25 \%$ & $12.50 \%$ & $100 \%$ & \\
\hline
\end{tabular}

Table 4. MRT results at $\mathrm{Ybl}$

The proportion of students in the four above classes was almost the same at the two institutions. If we take into consideration these four classes and not the students' opening mean scores, we can find that according to MRT the spatial abilities of the students did not differ in September in the two different places.

On the base of the Tables 3 and 4 we prepared diagrams and compared them (Figure 8 and 9). In Sopron more percentage of poor students ( $86 \%$ ) and less percentage of under average students $(68 \%)$ could improve than the average. The percentages of the good and the above average students were close to the average. In Budapest the tendencies were quite different. The highest percentage of the originally good students could improve, while the least percentage of the average students showed improvement at the end. So, while the education at SKF encouraged the poor students most, the education at $\mathrm{Ybl}$ the good students. As there are fewer students in Sopron, it enables the teacher to work with them in small groups with several easier exercises. It may help to improve students with poorer spatial abilities.
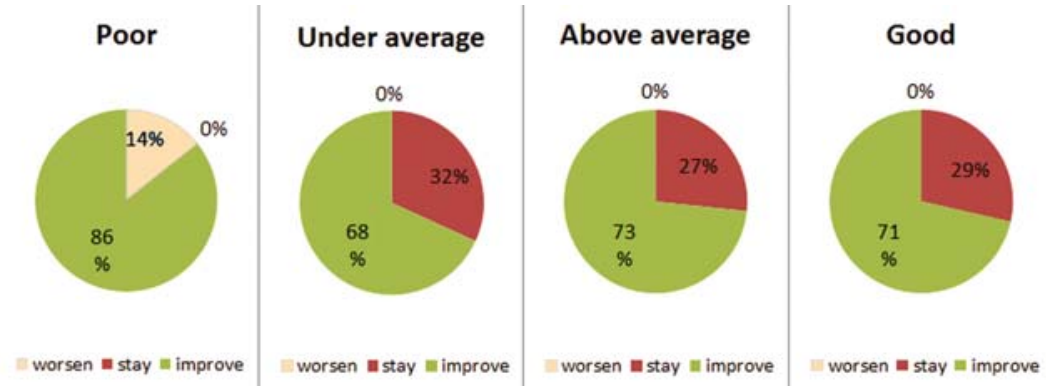

Figure 8. Improvement at SKF
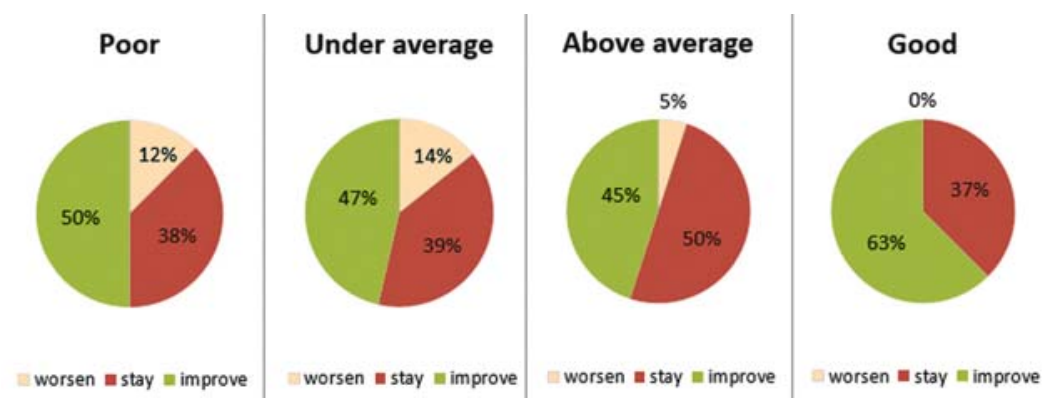

Figure 9. Improvement at $\mathrm{Ybl}$ 
In the followings we examine the rate of improvement in the different classes. Figure 10 shows the beginning and end-term mean scores of the classes. Each class in Sopron improved, while the class 40 declined at Ybl. (Actually, only one or two students belong to these classes, similarly to the classes 7 and 10.) The curve almost constantly grows with small peaks if we exclude the beginning and the end of the domain. Bigger mean score development can be seen in the originally lower classes. It also justifies the introduction of level of saturation by the authors of [3]. The curves show that the increase of scores is obviously bigger in each class at SKF, than at Ybl.
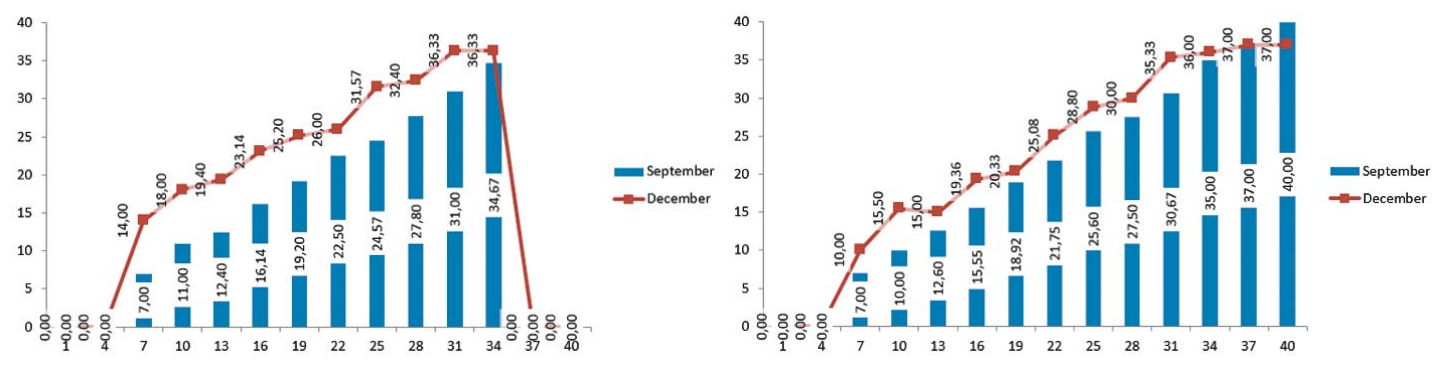

Figure 10. Improvements at SKF and at $\mathrm{Ybl}$

If we examine the increase by applying the level of saturation, we do not get a uniform result (Figure 11, 12 and 13). The small peaks of the curves found in Figure 10 equalize at the beginning of the domain and they intensify at the end, as it was expected from the properties of the level of saturation. The students with originally above average score improved the most, by $30-35 \%$ at SKF, while the good students improved the most at Ybl, by $38 \%$ and $50 \%$ (Figure 11). Although the class 34 improved only to a very small extent we must not forget, that only a few students belong to these upper classes, 7-8 students altogether in the upper 4 classes.
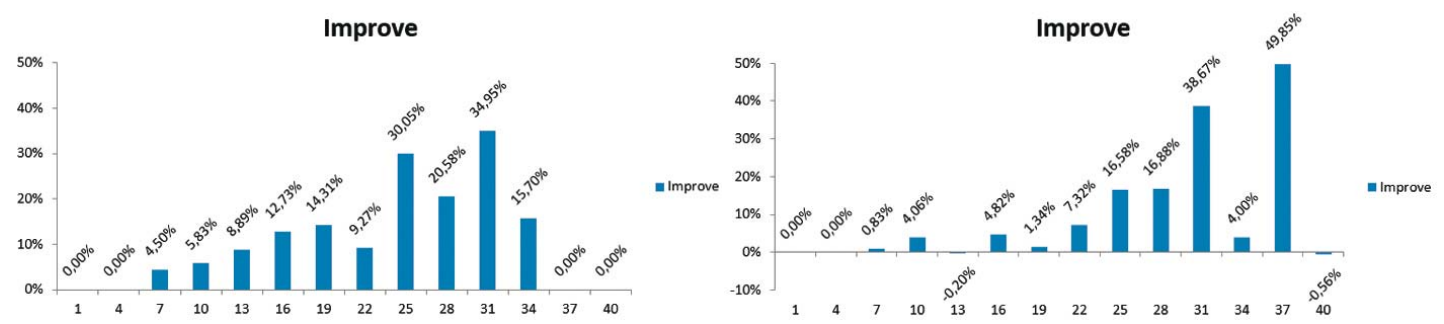

Figure 11. Improvements at SKF and at $\mathrm{Ybl}$
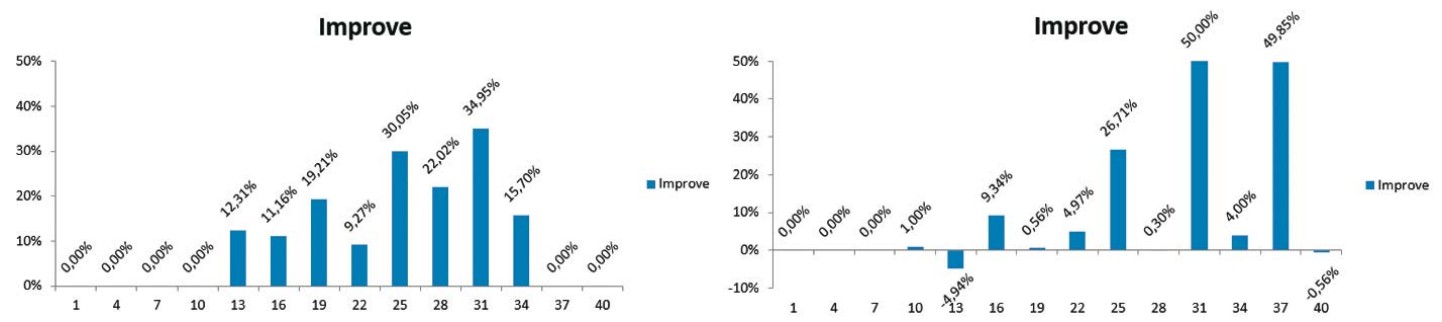

Figure 12. Improvements of males at SKF and at $\mathrm{Ybl}$ 


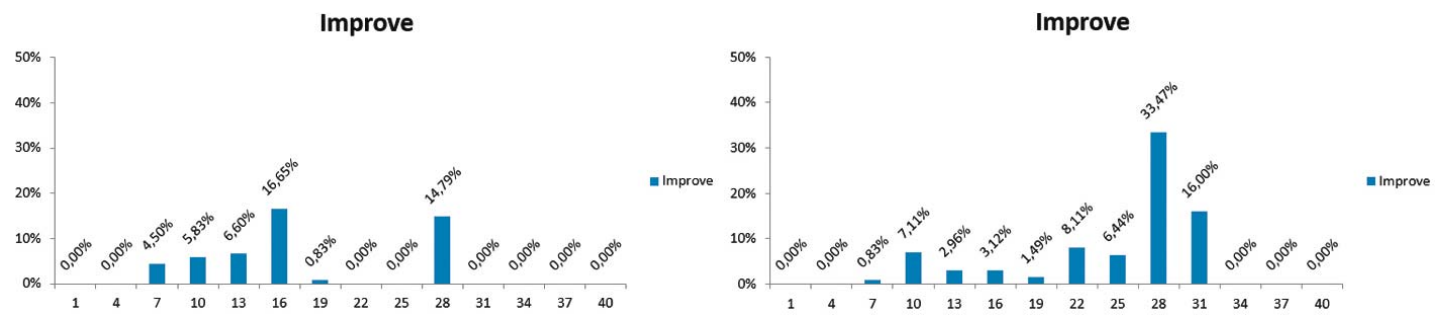

Figure 13. Improvements of females at SKF and at $\mathrm{Ybl}$

The graphs show that the improvement is uneven in the different classes in case of the architect students while all classes indicate growth after a semester study of Descriptive Geometry in Sopron. According to the spatial ability of better students improved more by taking into consideration the level of saturation.

It could be of great interest to compare the results in May of architect students with the results in December of engineer students at SKF, but unfortunately these results are not available at the moment of writing this article. But if we have a look at Table 5 with the data of the architect students in $2012 / 13$, we can see that $80 \%$ of the students improved, and only one wrote a worse test. On the base of [1], the average improvement was 7.62 points. Hopefully, the results in May 2014 will not differ from it considerably.

\begin{tabular}{|c|c|c|c|c|c|r|}
\hline $2012 / 13$ & poor & under average & above average & good & sum & \\
\hline worsen & 0 & 1 & 0 & 0 & 1 & $1.47 \%$ \\
\hline stay & 0 & 2 & 4 & 7 & 13 & $19.12 \%$ \\
\hline improve & 9 & 16 & 14 & 15 & 54 & $79.41 \%$ \\
\hline sum & 9 & 19 & 18 & 8 & 68 & $100 \%$ \\
\hline & $13.24 \%$ & $26.47 \%$ & $26.47 \%$ & $32.35 \%$ & $100 \%$ & \\
\hline
\end{tabular}

Table 5. MRT results at $\mathrm{Ybl}$ in academic year 2012/13 


\section{SUMMARY AND CONCLUSION}

Finally we summarize the observations of the MRT test results of students of wood industrial engineering and industrial design engineering of the Simonyi Károly Faculty of Engineering, Wood Sciences and Applied Arts of the University of West Hungary in Sopron and the architect students at the Ybl Miklós Faculty of Architecture and Civil Engineering of Szent István University in Budapest done at the beginning and the end of the first semester in the academic year 2013/14 in the Descriptive Geometry lessons.

- We can conclude that the test result improved by 5 points average at SKF and by 3 points at $\mathrm{Ybl}$ (Tables 1 and 2) during the semester. The increase in Sopron was quite good comparing to the results of previous surveys too.

- The results of female students even in December did not reach the results of male students' in September at both universities (Tables 1 and 2). It corresponds to the results of previous studies.

- The results of students at SKF in September can be estimated by a normal distribution at the $95 \%$ significance level (with a high peak), but not in December (Figure 1). The results of architect students at $\mathrm{Ybl}$ follow the normal distribution in both cases at the 95\% significance level (Figure 1).

Considering the students who wrote both MRT tests we can conclude:

- More students (72\%) developed in Sopron than in Budapest. The percentage of the male students who could improve was higher than the percentage of their developing female mates. This ratio was almost the same for the two genders at Ybl.

- On the base of their scores in September the proportion of students in the four spatial ability classes: poor, under average, above average, good was almost the same at the two institutions.

- In Sopron more percentage of poor students could improve while at Ybl more percentage of the originally good students could improve.

- If we examine the increase by applying the level of saturation, we can find that the improvement of students in Sopron was more constant and the students with originally above average score improved by more percentages.

We can state that according to MRT the spatial abilities of the students at the two institutions developed with a different extent. It all goes back mainly to the different structures of teaching Descriptive Geometry and the differences of other possible subjects that may develop spatial ability.

\section{ACKNOWLEDGMENTS}

We would like to express our special thanks to Attila Bölcskei who helped us in our work with useful advices. 


\section{REFERENCES}

[1] Bölcskei, A., Kovács, A. Zs., Kušar, D., New Ideals in Scoring the Mental Rotation Test, Ybl Journal of Built Environment, Volume 1, Issue 1 (2013), 59-69.

[2] Bölcskei, A., Gál-Kállay, Sz., Kovács, A. Zs., Sörös, Cs., Development of Spatial Abilities of Architect and Civil Engineer Students in the Light of the Mental Cutting Test, Journal for Geometry and Graphics, Volume 16 (2012), No 1, 97-109.

[3] BölcskeI, A., Kovács, A. Zs., Measurement of Spatial Abilities of Architect Students at Ybl Faculty by Mental Cutting Test (Hun), Debreceni Müszaki Közlemények, 2012(2), 35-44.

[4] Németh, B., Hoffmann, M., Gender differences in spatial visualization among engineering students, Annales Mathematicae et Informaticae, 33 (2006), 169-174.

[5] NéMeth, B., Measurement of development of spatial ability by Mental Cutting Test, Annales Mathematicae et Informaticae, 34 (2007), 123-128.

[6] Shepard, R. N., Metzler, J., Mental Rotation of Three-Dimensional Objects, Science, New Series, Vol. 171, No. 3972 (1971), $701-703$.

[7] Tsutsumi, E., Shiina, K., Suzaki, A., Yamanouchi, K. Saito, T., Suzuki K., A Mental Cutting Test on Female Students Using a Stereographic System, Journal for Geometry and Graphics, Volume 3 (1999), No. 1, 111-119.

[8] Tsutsumi, E., Schröcker, H.-P., Stachel, H., Weiss, G., Evaluation of Students' Spatial Abilities in Austria and Germany, Journal for Geometry and Graphics, Volume 9 (2005), No. 1, 107-117. 